\title{
Clinicopathological significance of CXCR4 in non-small cell lung cancer
}

This article was published in the following Dove Press journal:

Drug Design, Development and Therapy

5 March 2015

Number of times this article has been viewed

\author{
Xiao-ming Zhou' \\ Lan $\mathrm{He}^{2}$ \\ Gang $\mathrm{Hou}^{3}$ \\ Bing Jiang ${ }^{4}$ \\ Yuan-he Wang ${ }^{5}$ \\ Li Zhao'
}

'Department of Respiratory Medicine, The Shengjing Hospital of China Medical University, Shenyang, People's Republic of China; 2Department of Microbiology, The Chinese University of Hong Kong, Hong Kong SAR, People's Republic of China; ${ }^{3}$ Department of Respiratory Medicine, ${ }^{4}$ Department of

Ultrasonography, The First Hospital of China Medical University,

Shenyang, People's Republic of China; ${ }^{5}$ Department of Medical Oncology, Liaoning Cancer Hospital, Shenyang, People's Republic of China
Correspondence: Xiao-ming Zhou Department of Respiratory Medicine, The Shengjing Hospital of China Medical University, No 36 Sanhao Street, Shenyang, I 10004, People's Republic of China

Email xiaomingzhou0I@I63.com
Background: Emerging evidence indicates that C-X-C chemokine receptor type 4 (CXCR4) is a candidate oncogene in several types of human tumors including non-small cell lung cancer (NSCLC). However, the correlation between CXCR4 expression and clinicopathological characteristics of NSCLC remains unclear. Here, we conducted a meta-analysis to quantitatively evaluate the association of CXCR4 expression with the incidence of NSCLC and clinicopathological characteristics.

Methods: A detailed literature search was made from Medline and Web of Science for related research publications written in English and Chinese. The methodological quality of the studies was also evaluated. Analyses of pooled data were performed. Odds ratio (OR) and hazard ratio (HR) were calculated and summarized.

Results: The final analysis of 1,446 NSCLC patients from 13 eligible studies was performed. We observed that CXCR4 expression was significantly higher in NSCLC than in normal lung tissue from the pooled OR from five studies including 380 NSCLC and 118 normal lung tissue $(\mathrm{OR}=12.86,95 \%$ confidence interval $=3.63-45.59, P<0.0001)$. CXCR4 expression was not associated with smoking status and type of pathology. However, CXCR4 expression was significantly associated with clinical stages, metastatic status, and overall survival in NSCLC patients.

Conclusion: The results of this meta-analysis suggest that CXCR4 expression is associated with an increased risk and worse survival in NSCLC patients. The aberrant CXCR4 expression plays an important role in the carcinogenesis and metastasis of NSCLC.

Keywords: chemokine, clinicopathological factor, hazard ratio, meta-analysis, odds ratio

\section{Introduction}

Lung cancer is the second most common cancer and is the leading cause of cancer-related death in both men and women in the United States and throughout the world. ${ }^{1}$ Non-small cell lung cancer (NSCLC) - which includes the following histologic types: adenocarcinoma (AD), squamous cell carcinoma (SCC), large cell carcinoma, and mixed histologies - accounts for approximately $85 \%$ of all lung cancer and is the leading cause of cancer-related deaths worldwide. ${ }^{2,3}$ Despite the advances in early detection, radical cure operations, and multimodal therapeutic modalities, at diagnosis, there are about $80 \%$ of NSCLC cases in advanced stage, for which systemic chemotherapy remains the standard care but provides marginal improvement in survival. ${ }^{4}$ There is a major unmet medical need for effective and well-tolerated treatment options for patients with advanced NSCLC. Therefore, investigation into the mechanism of initiation and progression, as well as identification of prognostic markers, is still needed, and will help to identify patients with a high chance of lung cancer recurrence and provide better prognosis and individualization of treatment.

Chemokines are a group of small proteins that play a role in the immune system and in the progression of tumors; they are associated with cytoskeletal rearrangements, 
cell migration during development and physiology, and host immune response via interactions with $G$ protein-coupled receptors. ${ }^{5,6}$ The expression of chemokines leading to aberrant chemokine receptor signaling is altered in many malignancies. C-X-C chemokine receptor type 4 (CXCR4), also known as fusin or CD184, is an alpha-chemokine receptor specific for stromal-derived-factor-1 (SDF-1, also called CXCL12). ${ }^{7,8}$ CXCR4 belongs to the superfamily of seven transmembrane domain heterotrimeric $\mathrm{G}$ protein-coupled receptors, is functionally expressed on the cell surface of various types of cancer cells, and plays a role in the cell proliferation and migration of these cells. ${ }^{9-11}$ Recently, CXCR4 has been reported to play an important role in cell survival, proliferation, and migration, as well as in metastasis of several cancers including breast, ${ }^{12-14}$ cervical, ${ }^{15,16}$ colon or rectal, ${ }^{17,18}$ esophageal, ${ }^{18-20}$ gall bladder, ${ }^{21}$ kidney, ${ }^{22-24}$ liver, ${ }^{25,26}$ ovarian, ${ }^{27,28}$ pancreatic, ${ }^{29}$ prostate, ${ }^{30-32}$ stomach, ${ }^{33,34}$ uterine cancer, ${ }^{35}$ multiple myeloma, ${ }^{36,37}$ nonHodgkin lymphoma, ${ }^{38}$ etc.

A number of studies also showed that CXCR4 is also overexpressed in NSCLC and may account for its progression, metastasis, and prognosis. ${ }^{39-43}$ However, there still exists controversy. Wagner et al found that positive cytomembranous staining for CXCR4 is an independent indicator of poor prognosis, while nuclear staining confers a survival benefit to patients with $\mathrm{AD}$ of the lung. ${ }^{44}$ In addition, the roles of CXCR4 in NSCLC and clinical significance have not been thoroughly investigated. Meta-analysis has great advantages in confirming prognostic and pathological factors in cancer patients by avoiding the disadvantages of small sample size. Therefore, it is necessary to perform a pooled analysis using the results of published articles. In this study, we have analyzed and updated the published clinical investigations regarding the effect of CXCR4 on patients with NSCLC.

\section{Materials and methods}

\section{Search strategy and selection criteria}

We searched PubMed, Embase, and ISI Web of Knowledge to identify studies from January 1, 2000 to June 1, 2014 using the search terms: "lung" and "cancer" or "tumor" or "neoplasm" or "carcinoma"; "expression" and "CXCR4" or "C-X-C chemokine receptor type 4"; and "prognosis" or "prognostic" or "outcome". We also hand-searched the reference lists of the retrieved articles and reviews for additional articles. Conference abstracts were not selected for our analysis due to the insufficient data reported in them. After exclusion of nonrelevant and/or redundant publications from the different databases, the remaining papers were evaluated in the full text version for inclusion and exclusion criteria and for relevant articles in the reference lists. All searched data were retrieved. Authors' bibliographies and references of selected studies were also searched for other relevant studies. The most complete study was chosen to avoid duplication if the same patient populations were reported in several publications.

The criteria that an eligible study had to meet were as follows: 1) CXCR4 expression evaluated in the primary NSCLC tissues; 2) researches revealed the relationship between CXCR4 expression and NSCLC clinicopathological parameters and prognosis; and 3) studies provided sufficient information to estimate hazard ratio (HR) about overall survival (OS) and 95\% confidence interval (CI). The exclusion criteria included the following: 1) publications that were letters, reviews, case reports, conference abstracts, editorials, or expert opinion; and 2) all publications regarding in vitro/ ex vivo studies, cell lines, and human xenografts.

\section{Data extraction and methodological assessment}

Two authors (XMZ and LH) independently reviewed and extracted data from eligible studies. Disagreements were resolved by discussion and consensus. Two authors (XZ and $\mathrm{LH}$ ) reviewed all of the articles that fit the inclusion and exclusion criteria. The following information was recorded for each study: the first author name, year of publication, sample source, number of cases, clinicopathological parameters, cancer tumor node metastasis stage, immunohistochemical staining method, antibody source, percentage rate of expression, and follow-up. Data for study characteristics and clinical responses were summarized and the data turned into table format. Heterogeneity of investigation was evaluated to determine whether the data of the various studies could be analyzed for a meta-analysis.

For the methodological evaluation of the studies, three investigators (XZ, LH, and $\mathrm{GH}$ ) read through each publication independently, and assessed and scored them according to REMARK guidelines and the ELCWP quality scale. ${ }^{45,46}$ The three readers provided the quality scores and compared them, and then reached a consensus value for each item.

\section{Statistical analysis}

Analysis was conducted using the STATA 12.0 (StataCorp LP, College Station, TX, USA) and Review Manager 5.2 (Cochrane Collaboration, Oxford, UK). The pooled frequency of CXCR4 expression and 95\% CI were estimated. The frequency of CXCR4 expression was compared in different tumor characteristics. Heterogeneity among studies was evaluated with Cochran's Q test ${ }^{47}$ and the $I^{2}$ statistic. ${ }^{48,49}$ When heterogeneity 
was not an issue ( $I^{2}$ values $<50 \%$ ), a fixed effect model was used to calculate parameters. If there was substantial heterogeneity ( $I^{2}$ values $\geq 50 \%$ ), a random-effects model was used to pool data and attempt to identify potential sources of heterogeneity based on subgroup analyses. The pooled odds ratio (OR) was estimated for the association between CXCR 4 expression and clinicopathological features. $P$-values tailed less than 0.05 were considered statistically significant.

Publication bias was assessed by using a method reported by Egger et al..$^{50} \mathrm{We}$ also explored reasons for statistical heterogeneity using metaregression, subgroup analysis, and sensitivity analysis. The analysis of metaregression and publication bias was performed by using STATA version 10.0.

\section{Results}

\section{Identification of relevant studies}

Sixty-five publications were identified by the search method as described above. Fifty-two of those were excluded due to being laboratory studies, non-original articles (review), or studies irrelevant to the current analysis. Eventually, there were 13 studies included in final meta-analysis, as shown in Figure 1.

\section{Study characteristics}

Thirteen studies published from 2004 to 2014 were eligible for meta-analysis. A total of 1,446 NSCLC patients from People's Republic of China, Japan, France, Germany, Canada, and USA were enrolled. Their basic characteristics are summarized in Table 1. Positive CXCR4 expression was defined by immunohistochemistry. Most of studies defined positive CXCR4 expression as when any part of nucleus or cytoplasm was stained. There was difference in defining the cutoff value of positive CXCR4 expression. The majority of studies defined the cutoff value by combining intensity and percentage of CXCR4 expression, while the rest merely used the percentage of stained cells.

\section{The correlation of CXCR4 expression with clinicopathological features Increased CXCR4 expression in NSCLC}

We first determined whether CXCR4 expression is significantly higher in NSCLC than in normal lung tissue. The pooled OR from five studies including 380 NSCLC and 118 normal lung tissue, as shown in Figure $2(\mathrm{OR}=12.86$,

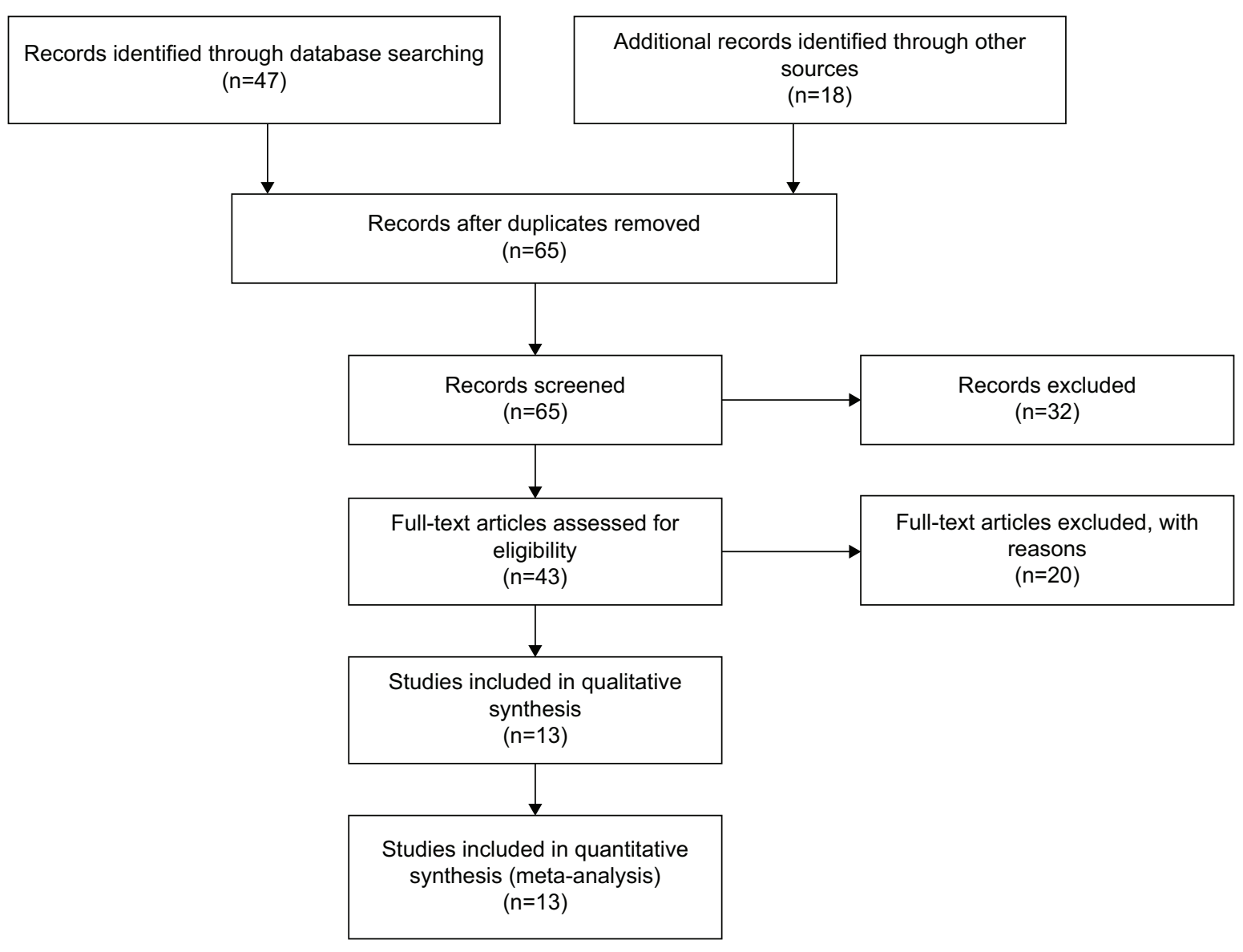

Figure I Flow chart of study selection. 
Table I Basic characteristics of the included studies

\begin{tabular}{|c|c|c|c|c|c|c|}
\hline Study & Country & Patients & Methods & Antibody source & CXCR4 distribution & $\begin{array}{l}\text { Definition of } \\
\text { CXCR4 positive }\end{array}$ \\
\hline Zhou et $\mathrm{a}^{61}$ & PRC & 105 & $\mathrm{IHC}$ & Beijing Boao Sen & Cytoplasm & $>5 \%$ \\
\hline Otsuka et $\mathrm{al}^{51}$ & Canada & 170 & $\mathrm{IHC}$ & Biotrend & Cytoplasm & $>10 \%$ \\
\hline Wang et $\mathrm{a}^{60}$ & PRC & 208 & $\mathrm{IHC}$ & $R \& D$ & Cytoplasm & $>5 \%$ \\
\hline Chen et $\mathrm{a}^{62}$ & PRC & 64 & $\mathrm{IHC}$ & Abcam Ltd. & $\begin{array}{l}\text { Membrane and/or } \\
\text { cytoplasm }\end{array}$ & $>5 \%$ \\
\hline Minamiya et $\mathrm{a}^{63}$ & Japan & 79 & IHC/Western blot & Leinco Technologies & Nucleus or cytoplasm & $>5 \%$ \\
\hline Wagner et $\mathrm{al}^{44}$ & United States & 154 & $\mathrm{IHC}$ & $R \& D$ & Nucleus and cytomembrane & $>_{+}$ \\
\hline $\mathrm{Na}$ et $\mathrm{a}^{64}$ & Germany & 44 & $\mathrm{IHC}$ & $R \& D$ & Cytoplasm and nucleus & $>1 \%$ \\
\hline Su et a ${ }^{65}$ & PRC & 34 & $\mathrm{IHC}$ & $R \& D$ & $\begin{array}{l}\text { Membrane and/or } \\
\text { cytoplasm }\end{array}$ & Level of intensity \\
\hline Suzuki et a $\left.\right|^{59}$ & Japan & 236 & $\mathrm{IHC}$ & $R \& D$ & Cytoplasm and/or nucleus & $>10 \%$ \\
\hline Spano et $a^{166}$ & France & 61 & $\mathrm{IHC}$ & Abcam Ltd. & Nucleus and/or cytoplasm & $>10 \%$ \\
\hline Hu et $\mathrm{a}^{67}$ & PRC & 66 & IHC/RT-PCR & Abcam Ltd. & Cytoplasm and/or nucleus & $>5 \%$ \\
\hline Zhang et $\mathrm{a}^{68}$ & PRC & 110 & $\mathrm{IHC}$ & $R \& D$ & $\begin{array}{l}\text { Membrane and } \\
\text { cytoplasm }\end{array}$ & $>10 \%$ \\
\hline Xiao et al ${ }^{69}$ & PRC & 115 & $\mathrm{IHC}$ & Boster & $\begin{array}{l}\text { Membrane and } \\
\text { cytoplasm }\end{array}$ & $>10 \%$ \\
\hline
\end{tabular}

Notes: Abcam Ltd.: Abcam Limited Biotechnology Europe, UK. Beijing Boao Sen: Beijing Boao Sen Biotechnology Co., Ltd. PRC. Biotrend: Biotrend Chemicals, LLC, Destin FL, USA. Boster: Boster, Pleasanton, CA, USA. Leinco Technologies: Leinco Technologies, Inc., St. Louis, MO, USA. R\&D: R\&D Systems, Inc., Minneapolis, MN, USA.

Abbreviations: IHC, immunohistochemistry; RT-PCR, reverse transcription polymerase chain reaction; PRC, People's Republic of China; CXCR4, chemokine receptor type 4; + , positive.

95\% CI=3.63-45.59, $P<0.0001)$, indicated that CXCR4 expression is significantly higher in NSCLC than normal lung tissue.

\section{Relationship between the frequency of CXCR4 expression and smoking status}

We then determined whether CXCR4 expression rate in NSCLC patients without a smoking history is significantly higher than that in patients with a smoking history. The pooled OR from four studies including 323 and 173 NSCLC with or without smoking history, respectively, as shown in Figure $3(\mathrm{OR}=1.22,95 \% \mathrm{CI}=0.79-1.89, P=0.37)$, indicated that CXCR4 expression was not strongly associated with the smoking status in NSCLC patients.

\section{Relationship between the frequency of CXCR4} expression and type of pathology

As previously reported, there was an obvious difference between CXCR4 expression in AD and SCC, indicating that CXCR4 expression in SCC may be associated with the development of these tumors. ${ }^{51,52}$ The pooled OR from eleven studies including $296 \mathrm{SCC}$ and $486 \mathrm{AD}$ is shown in Figure $4(\mathrm{OR}=1.46,95 \%$ $\mathrm{CI}=0.75-2.83, P=0.26$ ), and indicated that $\mathrm{CXCR} 4$ expression does not play a big role in the pathogenesis of SCC and AD.

The role of CXCR4 expression in NSCLC progression

We analyzed 736 NSCLC patients pooled from eight studies to assess whether CXCR4 expression in NSCLC was

\begin{tabular}{|c|c|c|c|c|c|c|c|c|}
\hline \multirow{2}{*}{$\begin{array}{l}\text { Study or subgroup } \\
\text { Xiao et } a^{69}\end{array}$} & \multirow{2}{*}{$\begin{array}{l}\text { NSCLC } \\
\text { Events } \\
60\end{array}$} & \multirow{2}{*}{$\begin{array}{l}\text { Total } \\
115\end{array}$} & \multicolumn{2}{|c|}{ Normal lung tissue } & \multirow{2}{*}{$\begin{array}{l}\text { Weight } \\
24.4 \%\end{array}$} & $\begin{array}{l}\text { OR } \\
M-H, \text { random, } 95 \% \mathrm{Cl}\end{array}$ & \multicolumn{2}{|c|}{$\begin{array}{l}\text { OR } \\
M-H \text {, random, } 95 \% \mathrm{Cl}\end{array}$} \\
\hline & & & 2 & 20 & & $9.82(2.18-44.27)$ & & \\
\hline Hu et $\mathrm{al}^{67}$ & 46 & 66 & 24 & 66 & $33.1 \%$ & $4.03(1.95-8.32)$ & & \\
\hline Spano et $a^{66}$ & 17 & 61 & 0 & 10 & $12.6 \%$ & $8.26(0.46-148.66)$ & & \\
\hline Su et $a^{65}$ & 34 & 36 & 0 & 10 & $11.4 \%$ & $289.80(12.87-6,523.35)$ & & \\
\hline Zhang et $a^{68}$ & 74 & 102 & 1 & 12 & $18.4 \%$ & $29.07(3.59-235.70)$ & & \\
\hline Total $(95 \% \mathrm{Cl})$ & & 380 & & 118 & $100.0 \%$ & $12.86(3.63-45.59)$ & & \\
\hline Total events & 231 & & 27 & & & & & \\
\hline \multicolumn{6}{|c|}{ Heterogeneity: $\tau^{2}=1.12 ; \chi^{2}=10.04, d f=4(P=0.04) ; I^{2}=60 \%$} & & 0.1 & \\
\hline \multicolumn{6}{|c|}{ Test for overall effect: $z=3.96(P<0.0001)$} & \multicolumn{2}{|c|}{$\begin{array}{ll}0.01 & 0.1 \\
\text { Favors (experimental) }\end{array}$} & Favors \\
\hline
\end{tabular}

Figure 2 The pooled OR from five studies including 380 NSCLC and I I 8 normal lung tissue.

Notes: $\mathrm{OR}=12.86,95 \% \mathrm{Cl}=3.63-45.59, \mathrm{P}<0.000 \mathrm{I}$.

Abbreviations: $\mathrm{Cl}$, confidence interval; $\mathrm{M}-\mathrm{H}$, Mantel-Haenszel; NSCLC, non-small cell lung cancer; OR, odds ratio. 


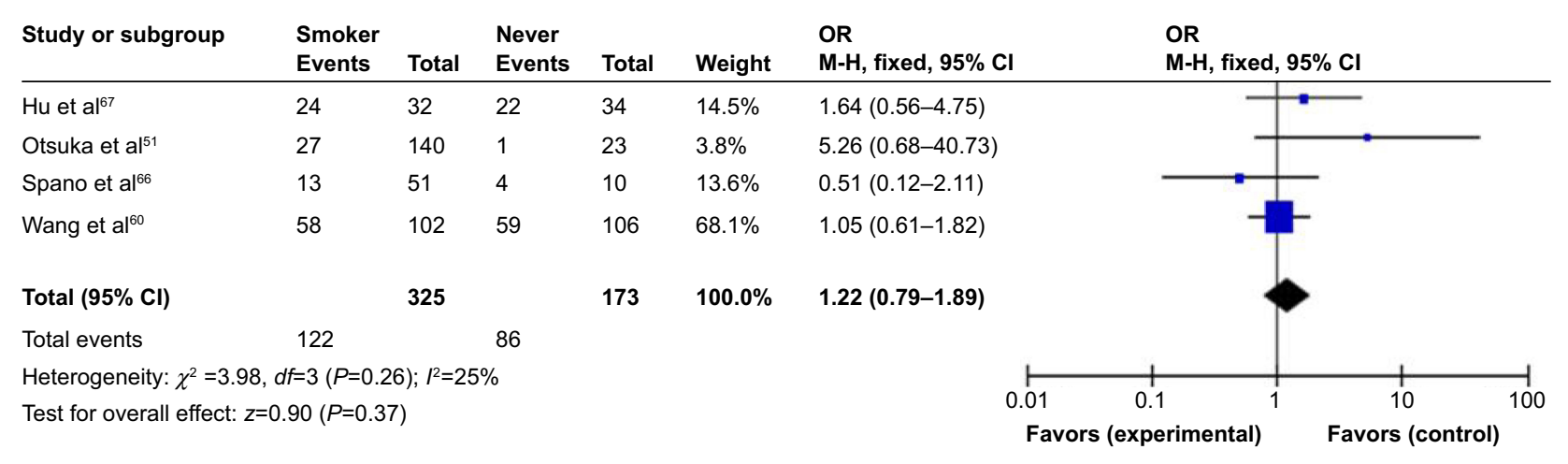

Figure 3 Four hundred and ninety-six NSCLC patients with the smoking status pooled in four studies.

Notes: Aberrant CXCR4 expression was not strongly associated with the smoking status in NSCLC patients $(\mathrm{OR}=1.22,95 \% \mathrm{Cl}=0.79-\mathrm{I} .89, \mathrm{P}=0.37)$.

Abbreviations: $\mathrm{Cl}$, confidence interval; $\mathrm{M}-\mathrm{H}$, Mantel-Haenszel; NSCLC, non-small cell lung cancer; OR, odds ratio; CXCR4, chemokine receptor type 4.

associated with advanced stage. As shown in Figure 5A, aberrant CXCR4 expression was significantly higher in advanced NSCLC (stages III and IV) than in early-stage NSCLC (stages I and II) $(\mathrm{OR}=2.33,95 \% \mathrm{CI}=1.13-4.82$, $P=0.02$ ). In addition, as shown in Figure 5B, aberrant CXCR4 expression was not significantly higher in poorly differentiated NSCLC than in moderately and highly differentiated NSCLC (OR=1.33, 95\% CI $=0.89-2.00, P=0.17)$. These results suggest that CXCR4 expression may not associate with tumor's differentiated status, but may play an important role in NSCLC progression and development.

The role of CXCR4 expression in metastatic

\section{NSCLC}

We then analyzed 1,049 NSCLC patients pooled from eleven studies to assess whether CXCR4 expression in NSCLC was associated with metastatic status. As shown in Figure 6, aberrant CXCR4 expression was significantly higher in metastatic NSCLC than in nonmetastatic NSCLC $(\mathrm{OR}=3.74$, $95 \% \mathrm{CI}=1.71-8.19, P=0.0009)$. These results suggest that CXCR4 expression is strongly correlated with metastatic status in NSCLC patients.

\section{CXCR4 expression as a prognostic factor for NSCLC}

Only four studies estimated the relationship between CXCR4 expression and OS in NSCLC. The pooled HR for OS showed that CXCR4 expression was significantly associated with worse survival in NSCLC patients as shown in Figure 7 $(\mathrm{HR}=3.26,95 \% \mathrm{CI}=2.22-4.79, P<0.00001)$.

\section{Sensitivity analyses and publication bias}

A sensitivity analysis, in which one study was removed at a time, was conducted to assess the stability of the results. The pooled ORs and HRs were not significantly changed, indicating the stability of our analyses. The funnel plots

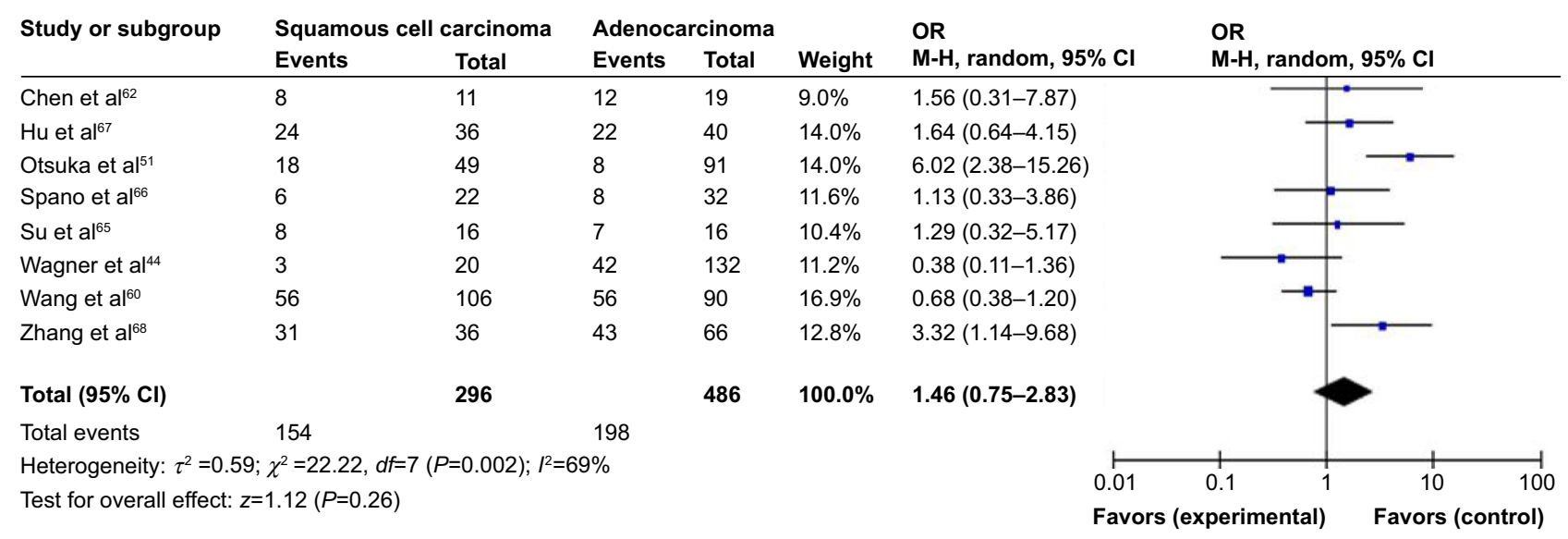

Figure 4 The pooled OR from eleven studies including 296 squamous cell carcinomas and 486 ADs.

Notes: $O R=1.46,95 \% \mathrm{Cl}=0.75-2.83, P=0.26$, which indicated that CXCR4 expression does not play a big difference in the pathogenesis of SCCs and AD.

Abbreviations: $A D$, adenocarcinomas; $\mathrm{Cl}$, confidence interval; $\mathrm{M}-\mathrm{H}$, Mantel-Haenszel; NSCLC, non-small cell lung cancer; OR, odds ratio; SCCs, squamous cell carcinomas; CXCR4, chemokine receptor type 4. 


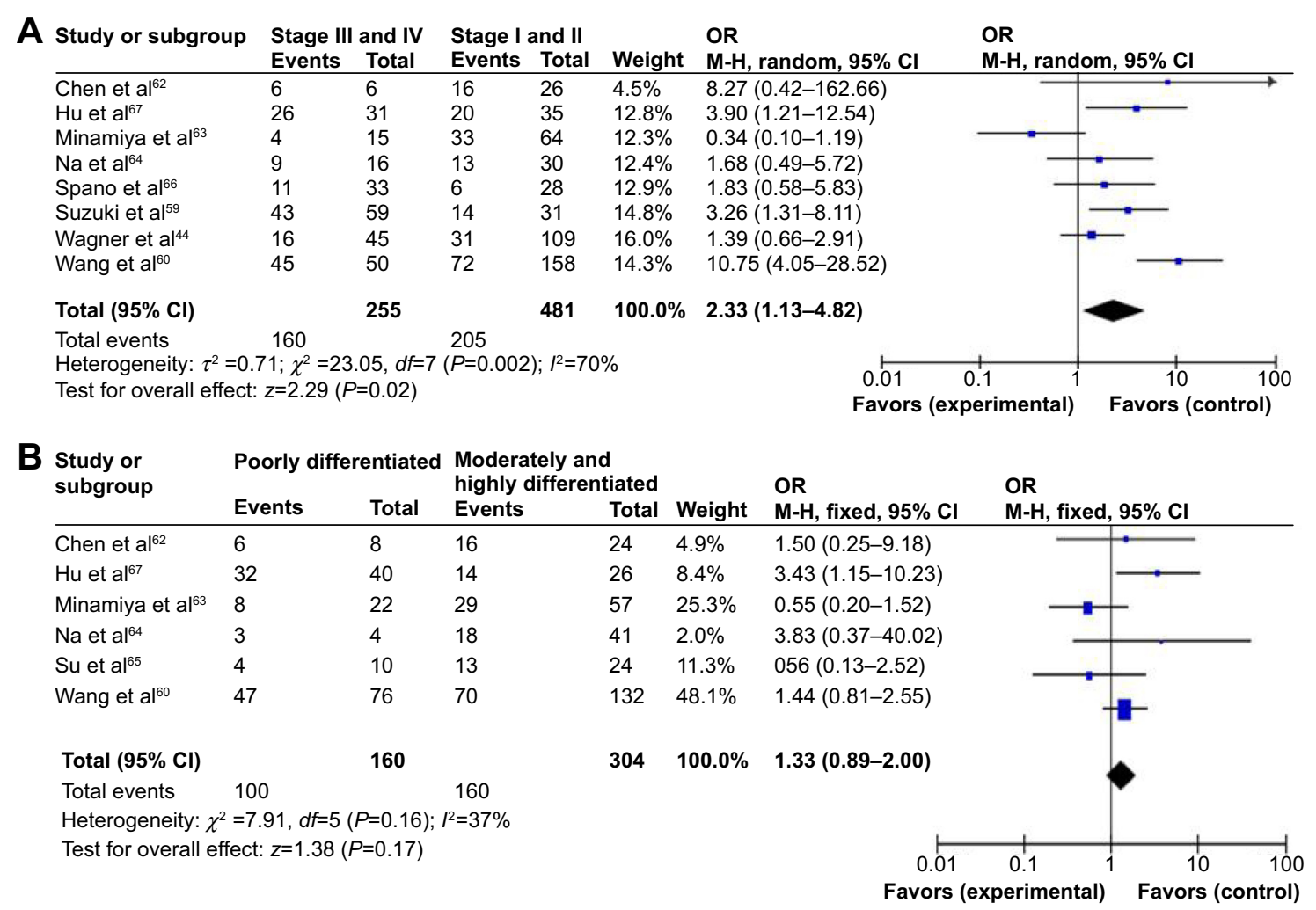

Figure 5 Seven hundred and thirty-six NSCLC patients pooled from eight studies to assess whether CXCR4 expression in NSCLC was associated with advanced stage. Notes: (A) CXCR4 expression was significantly higher in advanced NSCLC (stages III and IV) compared to in early-stage NSCLC (stages I and II) (OR=2.33, 95\% CI=I.I3-4.82, $P=0.02)$. (B) CXCR4 expression was not significantly high in poorly differentiated NSCLC compared to moderately and highly differentiated NSCLC (OR=I.33, Cl=0.89-2.00, $P=0.17)$.

Abbreviations: $\mathrm{Cl}$, confidence interval; M-H, Mantel-Haenszel; NSCLC, non-small cell lung cancer; OR, odds ratio; CXCR4, chemokine receptor type 4.

were largely symmetric (Figure 8) suggesting there were no publication biases in the meta-analysis of CXCR4 expression and clinicopathological features.

\section{Discussion}

Recently, many studies have shown that the presence of CXCR4 on lymphocytes and/or cancer cells can activate chemotaxis and signify proliferation, invasion, metastasis, and angiogenesis in several cancers, including NSCLC. ${ }^{9,13,41,53,54}$ To date, there have been some studies describing the precise expression and prognostic impact of CXCR4 in NSCLC; however, the roles and clinical significance of CXCR4 expression in NSCLC have not been thoroughly investigated. We conducted the meta-analysis to

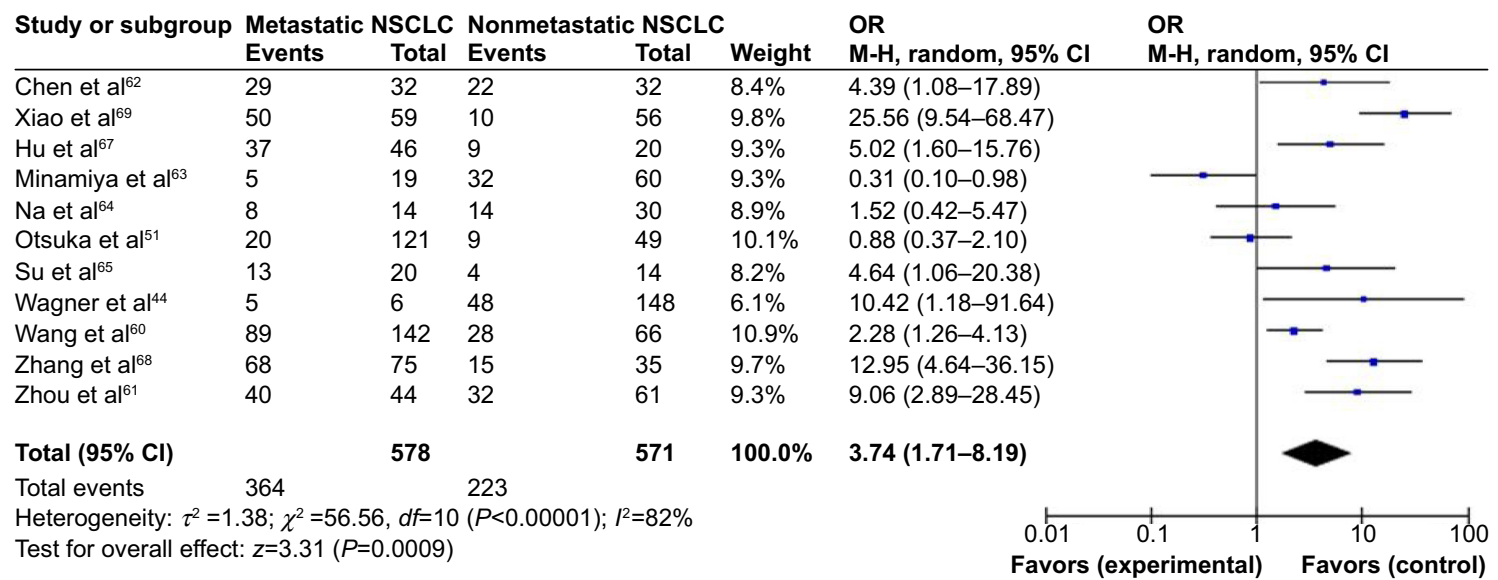

Figure 6 One thousand and forty-nine NSCLC patients pooled from eleven studies to assess whether CXCR4 expression in NSCLC was associated with metastatic status. Notes: CXCR4 expression was significantly higher in metastatic NSCLC compared to nonmetastatic NSCLC (OR=3.74, 95\% Cl=I.7I-8.19, $P=0.0009)$.

Abbreviations: $\mathrm{Cl}$, confidence interval; $\mathrm{M}-\mathrm{H}$, Mantel-Haenszel; NSCLC, non-small cell lung cancer; OR, odds ratio; CXCR4, chemokine receptor type 4. 


\begin{tabular}{|c|c|c|c|c|c|c|}
\hline Study or subgroup & Log (hazard ratio) & SE & Weight & $\begin{array}{l}\text { Hazard ratio } \\
\text { IV, fixed, } 95 \% \mathrm{CI}\end{array}$ & $\begin{array}{l}\text { Hazard } \\
\text { IV, fixed }\end{array}$ & $\begin{array}{l}\text { ratio } \\
\text { I, } 95 \% \mathrm{Cl}\end{array}$ \\
\hline Otsuka et al ${ }^{51}$ & 1.316 & 0.438 & $20.1 \%$ & $3.73(1.58-8.80)$ & & \\
\hline Suzuki et al ${ }^{59}$ & 1.52 & 0.565 & $12.1 \%$ & $4.57(1.51-13.84)$ & & \\
\hline Wagner et $\mathrm{al}^{44}$ & 0.602 & 0.368 & $28.5 \%$ & $1.83(0.89-3.76)$ & & \\
\hline Wang et $a^{60}$ & 1.429 & 0.313 & $39.4 \%$ & $4.17(2.26-7.71)$ & & \\
\hline \multicolumn{3}{|l|}{ Total $(95 \% \mathrm{Cl})$} & $100.0 \%$ & $3.26(2.22-4.79)$ & & \\
\hline \multicolumn{4}{|c|}{ Heterogeneity: $\chi^{2}=3.56, d f=3(P=0.31) ; l^{2}=16 \%$} & & & \\
\hline \multicolumn{4}{|c|}{ Test for overall effect: $z=6.02(P<0.00001)$} & $\begin{array}{l}0.01 \\
\text { Favors }\end{array}$ & perimental) $^{0.1}$ & $\begin{array}{r}10 \\
\text { Favor }\end{array}$ \\
\hline
\end{tabular}

Figure 7 Four of the included studies investigated the relationship between overall survival (OS) and CXCR4 expression.

Notes: The pooled HR for OS showed that CXCR4 expression was significantly associated with worse survival in NSCLC (HR=3.26, 95\% Cl=2.22 $-4.79, P<0.0000 \mathrm{I})$. Abbreviations: Cl, confidence interval; HR, hazard ratio; IV, inverse variance; NSCLC, non-small cell lung cancer; OS, overall survival; SE, standard error; CXCR4, chemokine receptor type 4 .

determine the correlation between CXCR4 expression and clinicopathological characteristics in NSCLC. Analyses of the pooled data showed that NSCLC had a higher CXCR4 expression than normal lung tissue. Aberrant CXCR4 expression was significantly higher in advanced NSCLC (stages III and IV) than in early-stage NSCLC (stages I and II). Aberrant CXCR4 expression was significantly higher in metastatic
NSCLC than in nonmetastatic NSCLC, and NSCLC patients with CXCR4 expression had a lower survival rate than those without CXCR4 expression. However, CXCR4 expression is not strongly associated with smoking status in NSCLC patients. CXCR4 expression does not make a big difference in the pathogenesis of SCC and AD. In addition, aberrant CXCR4 expression was not significantly higher in
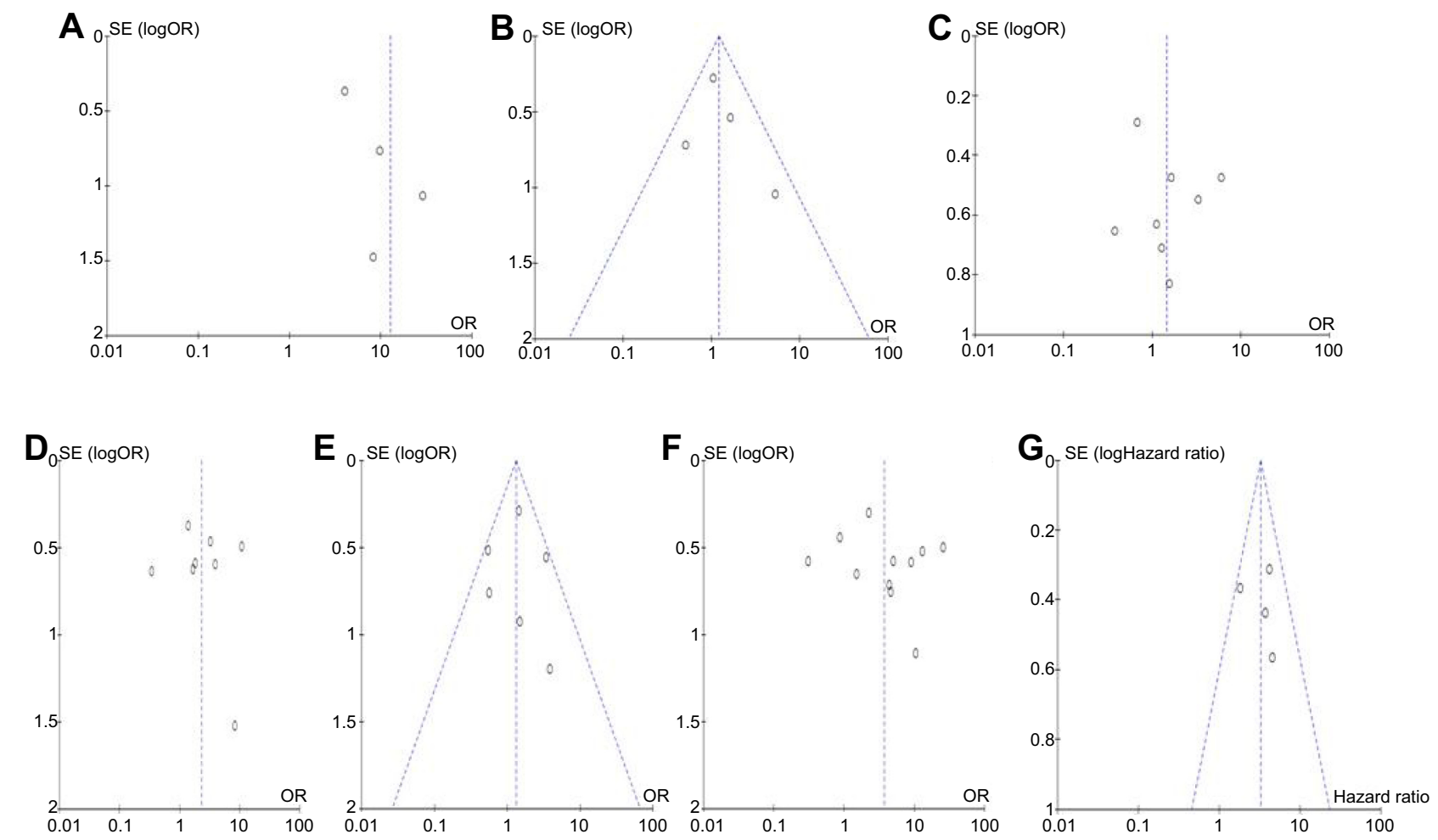

Figure 8 Funnel plots.

Notes: The funnel plots were largely symmetric suggesting there were no publication biases in the meta-analysis of CXCR4 expression and clinicopathological features. (A) The funnel plot from four studies comparing NSCLC and normal lung tissue. (B) The funnel plot from four studies in determining CXCR4 expression and smoking status in NSCLC patients. (C) The funnel plot from eight studies comparing CXCR4 expression between squamous cell carcinoma and adenocarcinoma. (D) The funnel plot from eight studies in determining CXCR4 expression for different stages of NSCLC. (E) The funnel plot from six studies in determining CXCR4 expression in different differentiated NSCLC. (F) The funnel plot from eleven studies in determining the relationship between CXCR4 expression and metastatic status in NSCLC. (G) The funnel plot from four studies in determining the relationship between CXCR4 expression and overall survival in NSCLC.

Abbreviations: NSCLC, non-small cell lung cancer; OR, odds ratio; CXCR4, chemokine receptor type 4. 
poorly differentiated NSCLC than in moderately and highly differentiated NSCLC. The results from the current study demonstrate that the expression rate of CXCR4 in NSCLC was significantly higher than that in the normal lung tissues, indicating that CXCR4 expression was common in NSCLC. CXCR4 expression may not be associated with tumor's differentiated status, but may play an important role in NSCLC progression and development. In addition, CXCR4 expression is strongly correlated with metastatic status and prognostic outcome in NSCLC patients. Information about the prognostic and predictive value of CXCR4 in NSCLC is limited. To our knowledge, this present meta-analysis is the first study to systematically evaluate the association between CXCR4 expression, clinicopathological features, and prognostic factors in NSCLC.

CXCR4 is pleiotropic during tumor suppression. CXCR4 mediates actin polymerization and pseudopodia formation, as well as induces chemotactic and invasive responses. ${ }^{11}$ Hence, CXCR4 plays an important role between tumor cells and the tumor microenvironment, with the interaction influencing the adhesion, migration, and invasion of tumor cells, reflecting the strong association of CXCR4 with cancer metastasis. CXCR4 expression on tumor cells is upregulated by hypoxia and angiogenic factors, such as vascular endothelial growth factor (VEGF) and hypoxia-inducible factor 1 (HIF-1); thus, CXCR4 could be a novel target of VEGF-, HIF-1-, and hypoxia-mediated angiogenesis. ${ }^{55-57} \mathrm{In}$ addition, SDF- $1 \alpha$ is the ligand for CXCR4, and SDF- $1 \alpha$, when highly expressed in NSCLC, has a significant role in tumor-relevant stem cell recruitment. ${ }^{41,58}$ Therefore, CXCR4 can be considered as an oncogene, and its activation could contribute to tumor progression and poor prognosis. Although only four studies evaluated the relationship between OS and CXCR4 expression in NSCLC, they showed very similar results..$^{44,51,59,60}$ Based on this meta-analysis, we may consider that CXCR4 expression in NSCLC tends to indicate a poor prognosis.

Consistent results were shown in sensitivity analyses, and no evidence of publication bias was found. This study has several potential limitations. First, the possibility of information and selection biases as well as unidentified confounders could not be completely excluded because all of the included studies were observational. Second, the searching strategy was restricted to articles published in English and Chinese. Articles with potentially highquality data that were published in other languages were not included because of anticipated difficulties in obtaining accurate medical translation. Third, the samples and studies were limited by a presence of heterogeneity between the studies. Statistical heterogeneity among the studies may be due to the differences in the baseline characteristics of patients, source of samples, normalization controls, technical platforms, source of antibodies, cut-off values, duration of follow-up, and other technical issues. In addition, the percentage of Asian population in the enrolled patients in some studies (Figures 2 and 5B) reached 90\%, raising a question of whether these results apply to other populations. Hence, cautions should be taken when our findings are interpreted among the general populations and in various ethnic populations.

\section{Conclusion}

Our meta-analysis showed that high CXCR4 expression was significantly higher in NSCLC than in normal lung tissue. In addition, CXCR4 expression was significantly associated with clinical stages, metastatic status, and OS in NSCLC patients. The results indicate that the aberrant CXCR4 expression plays an important role in the carcinogenesis and metastasis of NSCLC. It is thus safe to say that the remarkable potential of CXCR4 is as a prognostic biomarker for patients with NSCLC. Further large-scale studies, especially multicenter and well-matched cohort research, will provide more insight into the role of CXCR4 in the prognosis and clinical implementation of NSCLC patients.

\section{Disclosure}

The authors report no conflicts of interest in this work.

\section{References}

1. Jemal A, Siegel R, Xu J, Ward E. Cancer statistics, 2010. CA Cancer J Clin. 2010;60:277-300.

2. Siegel R, Naishadham D, Jemal A. Cancer statistics, 2012. CA Cancer J Clin. 2012;62:10-29.

3. Guo P, Huang ZL, Yu P, Li K. Trends in cancer mortality in China: an update. Ann Oncol. 2012;23:2755-2762.

4. Ramalingam S, Belani C. Systemic chemotherapy for advanced nonsmall cell lung cancer: recent advances and future directions. Oncologist. 2008;13 Suppl 1:5-13.

5. Sarvaiya PJ, Guo D, Ulasov I, Gabikian P, Lesniak MS. Chemokines in tumor progression and metastasis. Oncotarget. 2013;4:2171-2185.

6. Vinader V, Afarinkia K. The emerging role of CXC chemokines and their receptors in cancer. Future Med Chem. 2012;4:853-867.

7. Moriuchi M, Moriuchi H, Turner W, Fauci AS. Cloning and analysis of the promoter region of CXCR4, a coreceptor for HIV-1 entry. J Immunol. 1997;159:4322-4329.

8. Caruz A, Samsom M, Alonso JM, et al. Genomic organization and promoter characterization of human CXCR4 gene. FEBS Lett. 1998;426:271-278.

9. Cojoc M, Peitzsch C, Trautmann F, Polishchuk L, Telegeev GD, Dubrovska A. Emerging targets in cancer management: role of the CXCL12/CXCR4 axis. Onco Targets Ther. 2013;6:1347-1361.

10. Domanska UM, Kruizinga RC, Nagengast WB, et al. A review on CXCR4/CXCL12 axis in oncology: no place to hide. Eur J Cancer. 2013;49:219-230. 
11. Sun X, Cheng G, Hao M, et al. CXCL12/CXCR4/CXCR7 chemokine axis and cancer progression. Cancer Metastasis Rev. 2010;29: 709-722.

12. Zhang Z, Ni C, Chen W, et al. Expression of CXCR4 and breast cancer prognosis: a systematic review and meta-analysis. BMC Cancer. 2014;14:49.

13. Mukherjee D, Zhao J. The Role of chemokine receptor CXCR4 in breast cancer metastasis. Am J Cancer Res. 2013;3:46-57.

14. Hiller D, Chu QD. CXCR4 and axillary lymph nodes: review of a potential biomarker for breast cancer metastasis. Int J Breast Cancer. 2011;2011:420981.

15. Yang YC, Lee ZY, Wu CC, Chen TC, Chang CL, Chen CP. CXCR4 expression is associated with pelvic lymph node metastasis in cervical adenocarcinoma. Int J Gynecol Cancer. 2007;17:676-686.

16. Kodama J, Hasengaowa, Kusumoto T, et al. Association of CXCR4 and CCR7 chemokine receptor expression and lymph node metastasis in human cervical cancer. Ann Oncol. 2007;18:70-76.

17. Murakami T, Kawada K, Iwamoto M, et al. The role of CXCR 3 and CXCR4 in colorectal cancer metastasis. Int J Cancer. 2013;132:276-287.

18. Zeelenberg IS, Ruuls-Van Stalle L, Roos E. The chemokine receptor CXCR4 is required for outgrowth of colon carcinoma micrometastases. Cancer Res. 2003;63:3833-3839.

19. Gros SJ, Graeff H, Drenckhan A, et al. CXCR4/SDF-1 $\alpha$-mediated chemotaxis in an in vivo model of metastatic esophageal carcinoma In Vivo. 2012;26:711-718.

20. Gros SJ, Kurschat N, Drenckhan A, et al. Involvement of CXCR4 chemokine receptor in metastastic HER2-positive esophageal cancer. Plos One. 2012;7:e47287.

21. Yao X, Zhou L, Han S, Chen Y. High expression of CXCR4 and CXCR7 predicts poor survival in gallbladder cancer. $J$ Int Med Res. 2011;39: 1253-1264.

22. Huang CS, Tang SJ, Chung LY, et al. Galectin-1 upregulates CXCR4 to promote tumor progression and poor outcome in kidney cancer. J Am Soc Nephrol. 2014;25(7):1486-1495.

23. Wang L, Huang T, Chen W, et al. Silencing of CXCR4 by RNA interference inhibits cell growth and metastasis in human renal cancer cells. Oncol Rep. 2012;28:2043-2048.

24. Pan J, Mestas J, Burdick MD, et al. Stromal derived factor-1 (SDF-1/ CXCL12) and CXCR4 in renal cell carcinoma metastasis. Mol Cancer. 2006;5:56

25. Xiang Z, Zeng Z, Tang Z, et al. Increased expression of vascular endothelial growth factor-C and nuclear CXCR4 in hepatocellular carcinoma is correlated with lymph node metastasis and poor outcome. Cancer J. 2009;15:519-525.

26. Schimanski CC, Bahre R, Gockel I, et al. Dissemination of hepatocellular carcinoma is mediated via chemokine receptor CXCR4. Br J Cancer. 2006;95:210-217.

27. Wang J, Cai J, Han F, et al. Silencing of CXCR4 blocks progression of ovarian cancer and depresses canonical Wnt signaling pathway. Int J Gynecol Cancer. 2011;21:981-987.

28. Miyanishi N, Suzuki Y, Simizu S, Kuwabara Y, Banno K, Umezawa K. Involvement of autocrine CXCL12/CXCR4 system in the regulation of ovarian carcinoma cell invasion. Biochem Biophys Res Commun. 2010;403:154-159.

29. Park HD, Lee Y, Oh YK, et al. Pancreatic adenocarcinoma upregulated factor promotes metastasis by regulating TLR/CXCR4 activation. Oncogene. 2011;30:201-211.

30. Wong D, Kandagatla P, Korz W, Chinni SR. Targeting CXCR4 with CTCE-9908 inhibits prostate tumor metastasis. BMC Urol. 2014;14:12.

31. Cho KS, Yoon SJ, Lee JY, et al. Inhibition of tumor growth and histopathological changes following treatment with a chemokine receptor CXCR4 antagonist in a prostate cancer xenograft model. Oncol Lett. 2013;6:933-938.

32. Conley-LaComb MK, Saliganan A, Kandagatla P, Chen YQ, Cher ML, Chinni SR. PTEN loss mediated Akt activation promotes prostate tumor growth and metastasis via CXCL12/CXCR4 signaling. Mol Cancer. 2013;12:85.
33. Hashimoto I, Koizumi K, Tatematsu M, et al. Blocking on the CXCR4/ mTOR signalling pathway induces the anti-metastatic properties and autophagic cell death in peritoneal disseminated gastric cancer cells. Eur J Cancer. 2008;44:1022-1029.

34. Yasumoto K, Koizumi K, Kawashima A, et al. Role of the CXCL12/ CXCR4 axis in peritoneal carcinomatosis of gastric cancer. Cancer Res. 2006;66:2181-2187.

35. Gelmini S, Mangoni M, Castiglione F, et al. The CXCR4/CXCL12 axis in endometrial cancer. Clin Exp Metastasis. 2009;26:261-268.

36. Beider K, Begin M, Abraham M, et al. CXCR4 antagonist 4F-benzoylTN14003 inhibits leukemia and multiple myeloma tumor growth. Exp Hematol. 2011;39:282-292.

37. Azab AK, Runnels JM, Pitsillides C, et al. CXCR4 inhibitor AMD3100 disrupts the interaction of multiple myeloma cells with the bone marrow microenvironment and enhances their sensitivity to therapy. Blood. 2009;113:4341-4351

38. Bertolini F, Dell'Agnola C, Mancuso P, et al. CXCR4 neutralization, a novel therapeutic approach for non-Hodgkin's lymphoma. Cancer Res. 2002;62:3106-3112.

39. Choi YH, Burdick MD, Strieter BA, Mehrad B, Strieter RM. CXCR4, but not CXCR7, discriminates metastatic behavior in non-small cell lung cancer cells. Mol Cancer Res. 2014;12:38-47.

40. Al Zobair AA, Al Obeidy BF, Yang L, et al. Concomitant overexpression of EGFR and CXCR4 is associated with worse prognosis in a new molecular subtype of non-small cell lung cancer. Oncol Rep. 2013;29:1524-1532.

41. Wald O, Shapira OM, Izhar U. CXCR4/CXCL12 axis in non small cell lung cancer (NSCLC) pathologic roles and therapeutic potential. Theranostics. 2013;3:26-33.

42. Fahham D, Weiss ID, Abraham M, et al. In vitro and in vivo therapeutic efficacy of CXCR4 antagonist BKT140 against human non-small cell lung cancer. J Thorac Cardiovasc Surg. 2012;144:1167-1175.e1.

43. Reckamp KL, Figlin RA, Burdick MD, Dubinett SM, Elashoff RM, Strieter RM. CXCR4 expression on circulating pan-cytokeratin positive cells is associated with survival in patients with advanced non-small cell lung cancer. BMC Cancer. 2009;9:213.

44. Wagner PL, Hyjek E, Vazquez MF, et al. CXCL12 and CXCR4 in adenocarcinoma of the lung: association with metastasis and survival. J Thorac Cardiovasc Surg. 2009;137:615-621.

45. McShane LM, Altman DG, Sauerbrei W, et al. Reporting recommendations for tumor marker prognostic studies (REMARK). J Natl Cancer Inst. 2005;97:1180-1184.

46. Steels E, Paesmans M, Berghmans T, et al. Role of p53 as a prognostic factor for survival in lung cancer: a systematic review of the literature with a meta-analysis. Eur Respir J. 2001;18:705-719.

47. DerSimonian R, Laird N. Meta-analysis in clinical trials. Control Clin Trials. 1986;7:177-188.

48. Higgins JP, Thompson SG, Deeks JJ, Altman DG. Measuring inconsistency in meta-analyses. BMJ. 2003;327:557-560

49. DerSimonian R. Meta-analysis in the design and monitoring of clinical trials. Stat Med. 1996;15:1237-1248; discussion 1249-1252.

50. Egger M, Davey Smith G, Schneider M, Minder C. Bias in meta-analysis detected by a simple, graphical test. BMJ. 1997;315:629-634.

51. Otsuka S, Klimowicz AC, Kopciuk K, et al. CXCR4 overexpression is associated with poor outcome in females diagnosed with stage IV non-small cell lung cancer. J Thorac Oncol. 2011;6:1169-1178.

52. Zhang Y, Li H, Qi Y, Haofeng C, Shinan F, Chenkun W. Expression of CXCR4 in lung cancer tissue array and clinical significance. Chiese Medicine. 2012;36(2):78-82.

53. Nayak TR, Hong H, Zhang Y, Cai W. Multimodality imaging of CXCR4 in cancer: current status towards clinical translation. Curr Mol Med. 2013; $13: 1538-1548$

54. Lombardi L, Tavano F, Morelli F, Latiano TP, Di Sebastiano P, Maiello E. Chemokine receptor CXCR4: role in gastrointestinal cancer. Crit Rev Oncol Hematol. 2013;88:696-705.

55. Liekens S, Schols D, Hatse S. CXCL12-CXCR4 axis in angiogenesis, metastasis and stem cell mobilization. Curr Pharm Des. 2010;16: 3903-3920. 
56. Liu YL, Yu JM, Song XR, Wang XW, Xing LG, Gao BB. Regulation of the chemokine receptor CXCR4 and metastasis by hypoxia-inducible factor in non small cell lung cancer cell lines. Cancer Biol Ther. 2006;5:1320-1326.

57. Zagzag D, Lukyanov Y, Lan L, et al. Hypoxia-inducible factor 1 and VEGF upregulate CXCR4 in glioblastoma: implications for angiogenesis and glioma cell invasion. Lab Invest. 2006;86:1221-1232.

58. Imai H, Sunaga N, Shimizu Y, et al. Clinicopathological and therapeutic significance of CXCL12 expression in lung cancer. Int J Immunopathol Pharmacol. 2010;23:153-164.

59. Suzuki M, Mohamed S, Nakajima T, et al. Aberrant methylation of CXCL12 in non-small cell lung cancer is associated with an unfavorable prognosis. Int J Oncol. 2008;33:113-119.

60. Wang M, Chen GY, Song HT, Hong X, Yang ZY, Sui GJ. Significance of CXCR4, phosphorylated STAT3 and VEGF-A expression in resected non-small cell lung cancer. Exp Ther Med. 2011;2:517-522.

61. Zhou Z, Chen ZW, Yang XH, et al. Establishment of a biomarker model for predicting bone metastasis in resected stage III non-small cell lung cancer. J Exp Clin Cancer Res. 2012;31:34.

62. Chen G, Wang Z, Liu XY, Liu FY. High-level CXCR4 expression correlates with brain-specific metastasis of non-small cell lung cancer. World J Surg. 2011;35:56-61.
63. Minamiya Y, Saito H, Takahashi N, et al. Expression of the chemokine receptor CXCR4 correlates with a favorable prognosis in patients with adenocarcinoma of the lung. Lung Cancer. 2010;68:466-471.

64. Na IK, Scheibenbogen C, Adam C, et al. Nuclear expression of CXCR4 in tumor cells of non-small cell lung cancer is correlated with lymph node metastasis. Hum Pathol. 2008;39:1751-1755.

65. Su L, Zhang J, Xu H, et al. Differential expression of CXCR4 is associated with the metastatic potential of human non-small cell lung cancer cells. Clin Cancer Res. 2005;11:8273-8280.

66. Spano JP, Andre F, Morat L, et al. Chemokine receptor CXCR4 and early-stage non-small cell lung cancer: pattern of expression and correlation with outcome. Ann Oncol. 2004;15:613-617.

67. $\mathrm{Hu} \mathrm{T}$, Yao Y, Yu S, et al. [CXCR4 and Nrf2 expressions in non-small cell lung cancer and their clinical implications]. Nan Fang Yi Ke Da Хие Хие Bao. 2014;34:153-158. Chinese.

68. Zhang Y, Li H, Qi Y, Haofeng C, Shinan F, Chenkun W. Expression of CXCR4 in lung cancer tissue array and clinical significance. Guide of China Medicine. 2012;10(36):448-450.

69. Xiao T, Ren Y, Chen X, Liang L. Expression and Clinical Significance of Chemokine Receptor CXCR4 in Lung Cancer and Its Corresponding Lymph Node Metastasis. Clin J Med Offic. 2009;37(3):408-410.
Drug Design, Development and Therapy

\section{Publish your work in this journal}

Drug Design, Development and Therapy is an international, peerreviewed open-access journal that spans the spectrum of drug design and development through to clinical applications. Clinical outcomes, patient safety, and programs for the development and effective, safe, and sustained use of medicines are a feature of the journal, which

\section{Dovepress}

has also been accepted for indexing on PubMed Central. The manuscript management system is completely online and includes a very quick and fair peer-review system, which is all easy to use. Visit http://www.dovepress.com/testimonials.php to read real quotes from published authors. 